\title{
The Validity of Street Terms Used to Monitor the Australian Methamphetamine Market
}

\author{
Rebecca McKetin*, Jennifer McLaren and Erin Kelly
}

National Drug and Alcohol Research Centre, University of New South Wales, Sydney, Australia

\begin{abstract}
Aim: To validate the street terminology used to describe the various forms of methamphetamine used in Australia, namely 'speed' (powder methamphetamine), 'base' (a damp or oily product) and 'crystal meth' or 'ice' (crystalline methamphetamine).

Materials and Methodology: Regular methamphetamine users $(\mathrm{N}=309)$ were asked which form of methamphetamine they took on their last use occasion, and this was coded as: (a) speed/powder, (b) base, (c) crystal/ice or (d) other. Participants were then asked to identify which form of methamphetamine they used from an identification sheet that included photographs of each form of the drug. Receiver Operating Characteristics were used to determine the concordance between street terms and photographs of each form of methamphetamine.

Results: Street terms identified each respective form of methamphetamine in at least $85 \%$ of cases. However, these terms were more accurate in identifying crystalline methamphetamine (specificity $97 \%$, sensitivity $93 \%$ ) than other forms of the drug (speed/powder: specificity $92 \%$, sensitivity $89 \%$; base: specificity $92 \%$, sensitivity $65 \%$ ). This typology missed $12 \%$ of methamphetamine use occasions.

Conclusion: Street terminology can accurately identify crystalline methamphetamine in Australia, but caution is needed when using the terms 'speed' and 'base' to monitor these respective forms of the drug.
\end{abstract}

Keywords: Methamphetamine, amphetamine, street drugs, markets, terminology, substance abuse.

\section{INTRODUCTION}

Methamphetamine is a global drug problem, with an estimated 15 to 16 million consumers world-wide [1]. Understanding the methamphetamine market has been hindered by the various forms in which the drug is sold (e.g., tablets or ' $y a b a$ ', powder, crystalline methamphetamine, liquid and paste) $[2,3]$. In Southeast Asia smoking pills (ya ba) is the predominant pattern of methamphetamine use, while in neighbouring East Asian countries crystalline methamphetamine use is comparatively more common [2]. Crystalline methamphetamine also appears to be the dominant form of the drug in North America $[4,5]$ and South Africa [6]. In Australia the drug is available in powder and crystalline form, but it is also available in a damp or oily form called 'base' [3]. The consumer markets for different forms of methamphetamine are not necessarily mutually exclusive [7], which further complicates monitoring trends and understanding their health implications.

Despite these complications, previous research suggests that there is value in making a distinction between different forms of methamphetamine [8-14]. In particular, different forms of the drug have been suggested to reflect different supply pathways and/or production methods [3, 5]. Divergent trends have been noted between forms, with increasing use of crystalline methamphetamine in several

*Address correspondence to this author at the National Drug and Alcohol Research Centre, University of New South Wales, Sydney NSW 2052, Australia; Tel: + 6129385 0290; Fax: + 6129385 0222;

E-mail:r.mcketin@unsw.edu.au geographic regions $[9,12]$, which has been associated with an increased risk of methamphetamine-related harm [10,12]. Researching the implications of trends in crystalline methamphetamine use, or the use of other methamphetamine forms, however, relies on the integrity of the street terms that define each form of the drug.

In Australia, Topp and colleagues' have developed a typology to describe and monitor various forms of methamphetamine [3]. This typology has been adopted by illicit drug surveillance systems in Australia and elsewhere to monitor the methamphetamine market $[2,7-9,15,16]$ and to understand related harms [10-12]. It describes three forms of methamphetamine: (a) 'speed', a powder form of methamphetamine; (b) 'base', a sticky, waxy or oily form of damp powder, paste or crystal that has a yellow or brownish hue; and (c) 'ice', also known as 'crystal' and/or 'crystal meth': a high purity form of methamphetamine that consists of translucent to white crystals or a coarse crystalline powder. While this typology [3] details the physical characteristics of these methamphetamine forms and their street names, the accuracy of street terminology in identifying each form of methamphetamine has not been validated.

The aim of the current study was to validate the use of street terms to identify these various forms of methamphetamine [3]. This was done by comparing the self-reported use of each form of methamphetamine (speed/powder, base, ice/crystal, and other) against photographs of these methamphetamine forms. The accuracy of street terms in reflecting each form of methamphetamine was assessed using Receiver Operating Characteristics. 


\section{MATERIALS AND METHODOLOGY}

Participants were 309 methamphetamine users, who were recruited in Sydney through advertisements in free press publications, newspapers, websites, needle and syringe programs, and through word of mouth. Inclusion criteria for participation were being at least 16 years of age and having used methamphetamine at least monthly in the past year. A structured questionnaire was administered face-to-face by researchers at a mutually convenient location (e.g., cafes, parks and health centres). All participants were volunteers who completed written informed consent prior to the interview and were reimbursed AU $\$ 30$ for their time and travel expenses. The study was approved by the University of New South Wales Human Research Ethics Committee.

Participants were asked what form of methamphetamine they took on their most recent methamphetamine use occasion and this was recorded by the interviewer against the categories developed by Topp and colleagues [3]: (a) powder/speed, (b) base, (c) ice/crystal and (d) other or don't know. Participants then chose which form of the drug most closely resembled the methamphetamine that they had last used from an identification sheet (Fig. 1), where photographs A1-4 corresponded to speed/powder, B1-8 base; C1-3 ice/crystal and D1-4 were other forms of the drug that did not fall within with these pre-conceived categories. Photographs of methamphetamine were provided by the Australian Customs Service and the Victoria Police Forensic Services Centre.

The questionnaire also collected information on demographics, frequency of methamphetamine use in the past year (less than weekly, weekly, more than weekly but less than daily, daily or almost daily), forms of methamphetamine used in the past year according to the categories described by Topp and colleagues [3], and drug use history (lifetime, past year and past month use of all major drug classes). Dependence on methamphetamine was defined as a score of 4 or greater on the Severity of Dependence Scale [17, 18].

Statistical analysis of the data was undertaken using STATA SE version 10.0 [19]. Receiver Operating Characteristics analysis was used to assess the concordance between street terms used to describe categories of methamphetamine and photographs of each form.

\section{RESULTS}

\section{Participant Characteristics}

Participants had a median age of 28 years (range 16 to 60 years) and $59 \%$ were male. The majority were currently unemployed $(61 \%), 17 \%$ had part-time or casual work, only $14 \%$ were in full-time employment, $6 \%$ were students and $2 \%$ were engaged in home-duties. Twenty per cent were immigrants and $4 \%$ were from a non-English speaking background. One-third had a prison history. Polydrug use was common, with participants having used a median of seven drug classes in the past year (range 2 to 11). Participants had been using methamphetamine for a median of 10 years (range $<1$ year to 38 years). The majority $(64 \%)$ injected methamphetamine, $56 \%$ were dependent on the drug, and $82 \%$ had used it weekly or more often in the past year. The use of all forms of methamphetamine was high in the past year (speed $83 \%$, base $85 \%$, crystal $77 \%$ ).
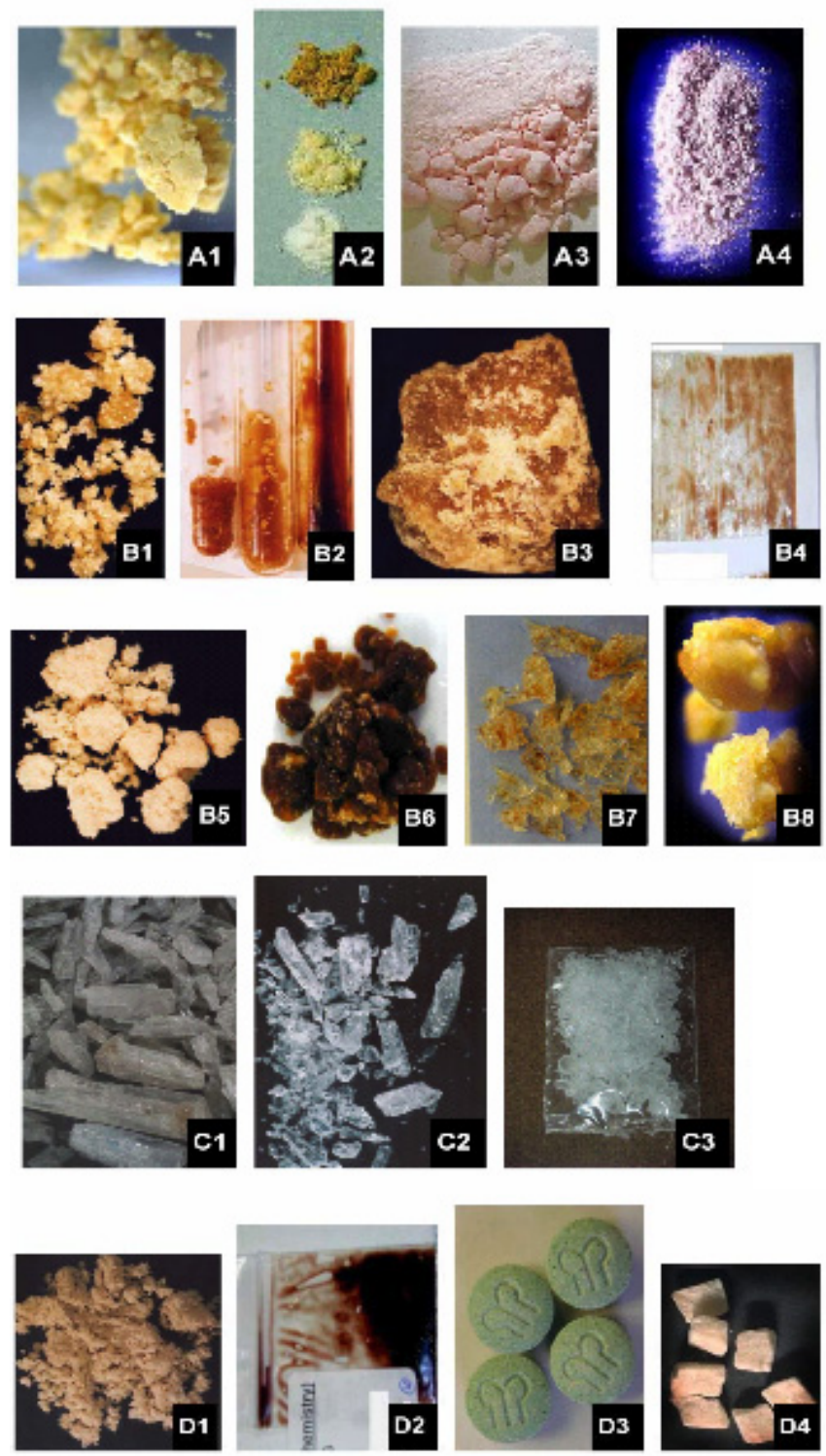

Fig. (1). Photographic identification sheet for methamphetamine forms (speed/powder A1-A3; base B1-B8; crystalline C1-C3; other D1-D4).

\section{Validation of the Methamphetamine Typology}

Street terminology correctly identified each form of methamphetamine in at least $85 \%$ of cases (Table 1). The street terms 'ice' or 'crystal' correctly identified photographs of crystalline methamphetamine (i.e., photographs $\mathrm{C} 1-3$ in Fig. 1) in $96 \%$ of cases, and yielded excellent sensitivity and specificity against this form of the drug (Table 1). These terms were rarely used to refer to other forms of methamphetamine (Table 2). The street term 'speed' showed a weaker, but nonetheless good, concordance with photographs of powder methamphetamine (i.e., A1-3 in Fig. 1, Table 1), although it was used to refer to other forms of methamphetamine in $23 \%$ of cases (Table 2 ).

The term 'base' was specific to pictures of base (i.e., the damp or oily forms of methamphetamine shown in B1-8 of Fig. 1) in $92 \%$ of cases, but it showed only moderate 
sensitivity against these photographs (Table 1), reflecting that other street terms were used in $35 \%$ of cases to describe this damp or oily form of the drug (typically the term 'pure', and less commonly 'speed'). Photographs of base that were most often nominated were those that looked like wet powder (i.e., B1 and B4 in Fig. (1) were nominated by $25 \%$ and $23 \%$ respectively, followed by D1 13\% and B8 11\%) and only one participant reported using base that had a crystalline appearance (B7 in Fig. 1). Several participants noted that 'base' looked like the photographs in B1-7 but was white.

Twelve per cent $(n=36)$ of participants nominated other terms for the form of methamphetamine they had last used, most commonly the term 'pure' $(n=18)$ which was typically used to refer to photographs of base (B1-8, in 14 of the 18 cases). occasions where an oily or damp form of the drug had been used. This may lead to an under-reporting of base consumption and biases in its reported price, availability and purity, which are routinely monitored by drug surveillance systems in Australia [13, 14]. Because other terms (particularly the term 'pure') was also used to describe this form of the drug, the accuracy of monitoring might be improved by providing drug users with a description of base methamphetamine rather than relying on street terms alone. Clarification is also needed around the characteristics of base methamphetamine: in contrast to earlier reports [3] 'base' rarely had a crystalline appearance, and although it often had a yellow or brownish hue, this was not a defining feature.

Monitoring systems that rely on this typology will also leave a small portion of the drug market unmonitored. This situation could become problematic if shifts in street

Table 1. Receiver Operating Characteristics for Street Terms Used to Describe Each Form of Methamphetamine Against the Photographic Identification Sheet

\begin{tabular}{|l|c|c|c|c|}
\hline \multirow{2}{*}{} & \multicolumn{2}{|c|}{ Street Term Used to Describe the Form of Methamphetamine Most Recently Used } \\
\cline { 2 - 5 } & $\begin{array}{c}\text { Speed/Powder } \\
(\mathbf{n}=\mathbf{8 5})\end{array}$ & $\begin{array}{c}\text { Base } \\
(\mathbf{n}=\mathbf{7 1})\end{array}$ & $\begin{array}{c}\text { Ice/Crystal } \\
(\mathbf{n}=\mathbf{1 1 7})\end{array}$ & $\begin{array}{c}\text { Other } \\
(\mathbf{n}=\mathbf{3 6})\end{array}$ \\
\hline \hline Sensitivity (\%) & 89 & 65 & 93 & 97 \\
\hline Specificity (\%) & 92 & 92 & 96 & 92 \\
\hline Correctly identified (\%) & 91 & 85 & $0.95(0.92-0.98)$ & $0.67(0.58-0.75)$ \\
\hline Area under the curve (95\% CI) & $0.90(0.86-0.94)$ & $0.78(0.72-0.84)$ & & \\
\hline
\end{tabular}

Table 2. Photographs of Methamphetamine Nominated for Each Street Term

\begin{tabular}{|c|c|c|c|c|}
\hline \multirow{2}{*}{} & \multicolumn{2}{|c|}{ Street Term Used to Describe the Form of Methamphetamine Most Recently Used } \\
\cline { 2 - 5 } & $\begin{array}{c}\text { Speed/Powder (\%) } \\
(\mathbf{n}=\mathbf{8 5})\end{array}$ & $\begin{array}{c}\text { Base (\%) } \\
(\mathbf{n}=\mathbf{7 1})\end{array}$ & $\begin{array}{c}\text { Ice/Crystal (\%) } \\
(\mathbf{n}=\mathbf{1 1 7})\end{array}$ & $\begin{array}{c}\text { Other (\%) } \\
(\mathbf{n}=\mathbf{3 6})\end{array}$ \\
\hline \hline Photograph nominated: & & & 1 & 8 \\
\hline Speed (A1-A4) & 77 & 5 & 3 & 43 \\
\hline Base (B1-B8) & 11 & 0 & 96 & 8 \\
\hline Ice/crystal (C1-C3) & 6 & 20 & 3 & 40 \\
\hline Other (D1-D4) & 6 & & & 8 \\
\hline
\end{tabular}

\section{DISCUSSION}

These findings show that the street terms used to describe the various forms of methamphetamine in Australia [3] are accurate in distinguishing between crystalline methamphetamine (ice/crystal) and other forms of the drug, but less robust for distinguishing between 'speed' and 'base'. While the term 'base' did accurately reflect the damp or oily methamphetamine described by Topp and colleagues' terminology, other terms were also used to describe this form of the drug (particularly the term 'pure'). The term 'speed' was used to refer to others forms of methamphetamine in about one-fifth of cases. This typology of methamphetamine forms missed $12 \%$ of methamphetamine use occasions.

A concern with the typology proposed by Topp and colleagues' [3] was that the term 'base' detected only $65 \%$ of terminology cause this unmonitored portion of the market to be inflated. However, it could be overcome, or at least detected, by monitoring methamphetamine use as a complete category (i.e., including all various forms of the drug and known street names), or actively monitoring 'other' forms of the drug.

Street terminology is parochial, and these findings should not be generalised to other geographic locations, particularly outside of Australia. These terms are also likely to vary over time, and differ between various sub-cultures of drug users. In particular, base methamphetamine is a phenomenon that has only been documented in Australia. This could reflect idiosyncratic production techniques or marketing of methamphetamine within Australia. However, the New Zealand street term for methamphetamine ('pure') was also 
to describe this same damp or oily form of methamphetamine, suggesting that it may occur in other countries, but that its existence has not been welldocumented.

Caution is also needed when interpreting the poor sensitivity of the term 'base' to identify damp or oily methamphetamine (i.e., a range of street terms were used to describe this damp/oily methamphetamine). While we found that participants often used the term 'pure' to refer to base methamphetamine, we cannot assume that they did not know that the term 'base' also referred to this damp or oily form of the drug. Also, we cannot be certain that the photographs of damp/oily methamphetamine in our identification sheet were indicative of base methamphetamine available on the Sydney illicit drug market.

\section{CONCLUSION}

In summary, the typology proposed by Topp and colleagues' [3] can accurately identify crystalline methamphetamine use, but it is less accurate in delineating between the use of other methamphetamine forms (i.e., 'speed' and 'base'). Caution is needed when using this typology to monitor drug trends. The lack of a clear distinction between base methamphetamine and other forms of the drug may bias trends in use, price and availability. For this reason, it is important to monitor 'other' forms of the drug (or methamphetamine use as a composite of its various forms) so that a complete picture of the methamphetamine market can be maintained.

\section{ACKNOWLEDGEMENTS}

This research was funded by the National Drug Law Enforcement Research Fund, Commonwealth of Australia, and the Australian Government Department of Health and Ageing. Thanks go to the staff associated with the Central, South Eastern Sydney and Wentworth Area Health Services in Sydney for assisting with the recruitment of participants. Photographs of methamphetamine seizures used in the identification sheet were provided by the Australian Customs Service and the Victoria Police Forensic Services Department. Finally, thanks go to Dr. Libby Topp and Adam Churchill, who developed the typology used in this paper, and came up with the idea of using photographs to aid their identification.

\section{REFERENCES}

[1] 2007 World Drug Report. Vienna: United Nations Office on Drugs and Crime 2007.
[2] Kozel N, Lund J, Douglas J, McKetin R. Patterns and trends in Amphetamine-Type Stimulants in East Asia and the Pacific 2006. Bangkok: United Nations Office on Drugs and Crime Regional Centre for East Asia and the Pacific 2007.

[3] Topp L, Degenhardt L, Kaye S, Darke S. The emergence of potent forms of methamphetamine in Sydney, Australia: A case study of the IDRS as a strategic early warning system. Drug Alcohol Rev 2002; $21: 341-8$.

[4] Cho AK. Ice: A new dosage form of an old drug. Science 1990; 249: 631-4.

[5] Maxwell JC, Rutkowski BA: The prevalence of methamphetamine and amphetamine abuse in North America: a review of the indicators, 1992-2007. Drug Alcohol Rev 2008; 27: 229-35.

[6] Morris K, Parry C. South African methamphetamine boom could fuel further HIV. Lancet Infect Dis 2002; 6: 471.

[7] McKetin R, McLaren J, Kelly E, Chalmers J. The market for crystalline methamphetamine in Sydney, Australia. Global Crime 2009; 10: 113-23.

[8] McKetin R, Kozel N, Douglas J, et al. The rise of methamphetamine in Southeast and East Asia. Drug Alcohol Rev 2008; 27: 220-8.

[9] Degenhardt L, Roxburgh A, Black E, et al. The epidemiology of methamphetamine use and harm in Australia. Drug Alcohol Rev 2008; 27: 243-52.

[10] McKetin R, McLaren J, Kelly E. The relationship between crystalline methamphetamine use and methamphetamine dependence. Drug Alcohol Depend 2006; 85: 198-204.

[11] Degenhardt L, Topp L. 'Crystal meth' use among polydrug users in Sydney's dance party subculture: characteristics use patterns and associated harms. Int J Drug Policy 2003; 14: 17-24.

[12] Kinner SA, Degenhardt L. Crystal methamphetamine smoking among regular ecstasy users in Australia: Increases in use and associations with harm. Drug Alcohol Rev 2008; 7: 292-300.

[13] Furr J, Delva CDM, Anthony JC. The suspected association between methamphetamine ('ice') smoking and frequent episodes of alcohol intoxication: data from the 1993 National Household Survey on Drug Abuse. Drug Alcohol Depend 2000; 59: 89-93.

[14] Bungay V, Malchy L, Buxton JA, Johnson J, Macpherson D, Rosenfeld T. 'Life with jib', A snapshot of street youth's use of crystalline methamphetamine. Addict Res Theory 2006: 14: 23551 .

[15] Black E, Roxburgh A, Degenhardt L, et al. Australian drug trends 2007: Findings from the Illicit Drug Reporting System (IDRS). [Australian Drug Trends Series No. 1]. Sydney: National Drug and Alcohol Research Centre 2008.

[16] Black E, Dunn M, Degenhardt L, et al. Australian trends in ecstasy and related drug markets 2007: Findings from the Ecstasy and Related Drugs Reporting System (EDRS). [Australian Drug Trends Series No. 10]. Sydney: National Drug and Alcohol Research Centre 2008.

[17] Topp L, Mattick RP. Choosing a cutoff on the Severity of Dependence Scale (SDS) for amphetamine users. Addiction 1997; 92: 839-45.

[18] Gossop M, Griffiths P, Powis B, Strang J. Severity of dependence and route of administration of heroin, cocaine and amphetamines. Br J Addict 1992; 87: 1527-36.

[19] STATA/SE Version 10.0 for Windows. Texas: STATA Cooperation 2006.

(C) McKetin et al.; Licensee Bentham Open.

This is an open access article licensed under the terms of the Creative Commons Attribution Non-Commercial License (http://creativecommons.org/licenses/by$\mathrm{nc} / 3.0 /$ ) which permits unrestricted, non-commercial use, distribution and reproduction in any medium, provided the work is properly cited. 